\title{
EVALUACIÓN DE LA ESCUELA MODERNA EN LA DIDÁCTICA DE LAS IDEAS IGUALITARIAS. ¿UNA PRIMITIVA EDUCACIÓN FEMINISTA?
}

\section{ASSESSMENT OF THE MODERN SCHOOL IN THE DIDACTICS OF EGALITARIAN IDEAS. A PRIMITIVE FEMINIST EDUCATION?}

\section{Antonio Nadal Masegosa}

Universidad de Málaga, Málaga, España.

antonionm@uma.es

Recibido: octubre de 2021 Aceptado: noviembre de 2021

\footnotetext{
Palabras clave: Análisis cualitativo, educación, Escuela Moderna, evaluación, historia de la educación, mujer.

Keywords: Qualitative analysis, education, Modern School, evaluation, history of education, woman.
}

Resumen: El papel de la mujer en la Escuela Moderna, experiencia pedagógica de principios del siglo XX, y básica e internacionalmente conocida por el fusilamiento, en 1909, de su creador, Francisco Ferrer Guardia, es una temática interesante de investigación. Añadido a ello, y quizás aún más importante, es conocer cómo se transmitía -y si así realmente sucedía- una educación igualitaria, y cómo se enfrentaba a una arcaica sociedad de múltiples formas, a través de la coeducación de niñas y niños, y de publicaciones específicas dentro del Boletín de la Escuela Moderna, órgano de expresión del centro educativo.

Abstract: The role of women in the Modern School, a pedagogical experience from the beginning of the 20th century, and basically and internationally known for the execution, in 1909, of its creator, Francisco Ferrer Guardia, is an interesting research topic. Added to this, and perhaps even more important, is to know how an egalitarian education was transmitted -and if it really happened-, how it faced an archaic society in multiple ways, through coeducation of girls and boys, and with specific publications within the Modern School Bulletin, the journal of this educational place.

\section{l. Introducción}

Imaginemos un Estado español en el cual la Inquisición se había abolido hacía solo poco más de 60 años. Una población con un altísimo analfabetismo, con una am- 
plísima incultura, unos niveles de trabajo infantil considerables, un régimen que tenía a una creciente población, procedente en gran parte del entorno rural, bajo los dictámenes de una nueva dictadura industrial, en la cual la producción, bajo la consideración de las personas como meros recursos humanos, era la norma. Una enseñanza en manos casi al 100\% de la Iglesia Católica, con escuelas, relativamente escasas, destinadas mayoritariamente a la élite, y que segregaban a niños y a niñas. Aún hoy, en el Estado español, y un considerable número de lugares en el planeta, hay escuelas que segregan, por no hablar de las atrocidades que pudieran narrarse de lugares como Afganistán o Arabia Saudí. En el entorno, por una parte, menos propicio que podamos imaginar, iba a nacer una escuela que pretendía, desde la enseñanza, revertir todo lo narrado, siendo una de sus herramientas la coeducación de niñas y niños (Nadal, 2019a).

Pero también hemos de considerar otro contexto. Pese a que, en el Estado español, los niveles de ilustración alcanzados en otros lugares europeos no eran los mismos, la Barcelona de aquel tiempo -finales del siglo XIX, principios del XX-, sin ser el París o Londres de la época, sí era un espacio con un interés creciente por la ciencia y el conocimiento, así como un territorio en el cual el movimiento obrero, pese a sufrir duros golpes y represiones previas, seguía en marcha, y era, crecientemente, consciente de la importancia que conllevaba la instrucción, y así lo atestiguaban sus escritos y resoluciones congresuales.

La Escuela Moderna, por tanto, de inicio, trataría de abrirse paso entre hostilidades $\mathrm{y}$ afinidades, pero teniendo en cuenta el enorme poder de quienes nada tenían que ver ni con su práctica, ni con su ideario, ni por supuesto con sus fines transfor- madores y emancipadores. De hecho, la coeducación de niñas y niños se iniciaría haciendo el menor ruido posible, ese ruido que hoy, aún, no desean, en determinados casos, las instituciones públicas o privadas para que no se cuestione nada de sus prácticas.

No era sencilla la tarea, puesto que, además, existía la necesidad de que familias confiaran a sus hijas a la Escuela Moderna, con más factores añadidos. Difícilmente, en la Barcelona de la época, para algunos núcleos familiares, era posible prescindir de la labor de las niñas, ya fuera como cuidadoras de familiares con enfermedades, de niños y niñas aún más pequeños/as, o incluso como trabajadoras en industrias o el campo. Sumemos a ello el precio de la matrícula de la escuela. Ello podría hacernos pensar que las niñas que asistieron a la Escuela Moderna fueron, si es que era una categoría válida para la época, de clases medias, acomodadas, burguesas. Difícil establecerlo por los apellidos del alumnado, pero sí que sería cierto que habría algo así como una matrícula progresiva en función de la capacidad adquisitiva de madres y padres, y más verídico aún, que la escuela, pública probablemente en el sentido más estricto de la palabra, siempre fue deficitaria en lo económico, pero esto, realmente, no afectaría, básicamente, a su viabilidad real. La causa de ello, de la frase anterior, y sigue omitiéndose -como tantas otras cuestiones, cuando se habla de la Escuela Moderna, y cuando se tratan tan alto número de temáticas-, cómo no, era debido a un hecho relacionado con una mujer, sin la cual no existiría la Escuela Moderna. Esto lo veremos más adelante.

El objetivo del presente artículo es mostrar una experiencia que tantas veces queda fuera de la historia del feminismo 
y de la educación emancipadora, desde el análisis y la evaluación, atendiendo a los diversos condicionantes, para lograr comprender cómo las ideas igualitarias no solo se escriben, o difunden, sino que se practicaron, dentro de un entorno no precisamente propicio.

\section{Por qué llamarlo solo contexto histórico, cuando podemos llamarlo contexto patriarcal. La resistencia}

Algunos datos pueden ponernos en situación -sobre todo para las y los lectores más jóvenes-, ya que es muy importante contextualizar y, a ser posible, no alejarnos en demasía de la comparación con la realidad actual, de la que venimos. Por ejemplo, en el Estado español, salvo en el pequeño intervalo de la II República, las mujeres no han tenido el derecho a divorciarse hasta 1981 y, aún entonces, la aprobación de la Ley del Divorcio trajo consigo una considerable polémica (Martín de Santa Olalla, 2001).

Tras la promulgación de la Ley 14/1975, de 2 de mayo, sobre reforma de determinados artículos del Código Civil y del Código de Comercio sobre la situación jurídica de la mujer casada y los derechos y deberes de los cónyuges, las mujeres comenzaron a tener la mera opción de abrirse una cuenta bancaria, por ejemplo. Es decir, solo a partir de entonces, "comienza la redención de la mujer, suprimiendo la licencia marital y dotándola de capacidad de obrar por sí sola" (Zarraluqui, 2012: 3). La discriminación y desigualdad de las mujeres en el Estado español durante la práctica totalidad del siglo XX implican un buen número de actividades que las mujeres, por el mero hecho de serlo, no podían hacer y que, en la actualidad, en gran parte, son considerados derechos (Rodríguez, 2019).

Si el contexto inmediatamente posterior a la Escuela Moderna no estuvo precisamente, ni tan siquiera, próximo a la aplicación de los derechos humanos con respecto a las mujeres, hasta el final de la dictadura franquista, el previo tampoco le fue especialmente favorable. Las madres de las hijas de las alumnas de la Escuela Moderna habían sido (de)formadas para un rol fundamental, asignándoseles, durante la segunda mitad del siglo XIX, el cuidado de la familia y la crianza de la descendencia, quedando, en teoría, restringido prácticamente todo lo demás (Saloma, 2000).

No sería estrictamente necesario dedicar páginas y páginas a la represión política, social, y en todos los ámbitos de la vida cotidiana, que sufrían las mujeres, pues ya las habría. Sin embargo, hay otra historia, de la cual es posible que no haya tantas páginas escritas, pero que contribuye a la forja de un sueño, y de los inicios del feminismo. Esas familias monoparentales de mujeres, esas prostitutas organizadas teniendo en cuenta las condiciones de la época, esas niñas que eran cabeza de familia mientras que sus padres y madres trabajaban, ocupándose de personas dependientes y niños y niñas de más corta edad, y todo ese número, creciente con la industrialización de Barcelona, en este caso, que eran tan clase trabajadora como los hombres, y que la historia no puede ignorar por más tiempo (Marín, 2009). Hay más. En la creciente lucha obrera de finales del siglo XIX y principios del siglo $\mathrm{XX}$, los patrones tradicionales de acción colectiva en la calle -tanto en Cataluña como fuera de ella- se materializaban en 
forma de ataques a las oficinas donde se recaudaban los consumos y levantamiento de barricadas, y ahí estaban las mujeres, cuya presencia llegaba hasta el punto de encabezar manifestaciones y a la vez actuar como diques contra la represión militar (Rubí, 2011).

Aún hoy, sigue siendo bastante desconocido el papel que tuvieron mujeres como Louise Michel, que, desde la Comuna de París, fue todo un referente de lucha, también muy vinculada con la educación ( $\mathrm{Di}$ Paola, 2021). No es casual, y no lo olvidemos: probablemente nos llegaría antes información sobre un feminismo primitivo que derivó en ultraderecha y nazismo (Ortega, 2016), que sobre la primera organización feminista fundada y dirigida por mujeres, como fue la Sociedad Autónoma de Mujeres de Barcelona, activa a partir de 1889, e impulsada por la espiritista Amalia Domingo Soler, la anarquista Teresa Claramunt y la republicana, masona y librepensadora Ángeles López de Ayala (Montagut, 2010). Se conoce, y se difunde, hasta por el partido político español Ciudadanos (Nerín, 2018), a Clara Campoamor, omitiéndose el verdadero origen de las organizaciones feministas, obviándose que la citada Teresa Claramunt, precisamente, fue la Louise Michel de Sabadell, Barcelona (Fernández, 2018). El feminismo burgués que nos vende que el sufragismo era el objetivo de la lucha de las mujeres, y que esto es lo que debe enseñarse en sus centros de enseñanza y medios de comunicación, bajo mi punto de vista, está bastante alejado de lo que realmente pretendió el movimiento feminista primitivo: el "feminismo catalán de principios de siglo no se centrará en la demanda del voto ni en los derechos políticos de las mujeres. En lugar del sufragismo, promueve los derechos de las mu- jeres en los ámbitos educativos, culturales y laborales" (Pradas, 2006: 115).

Un hecho histórico a destacar, en el sentido de lo que se viene comentando, sería la huelga de las siete semanas del sector textil de Sabadell de 1883, con la citada Claramunt entre sus protagonistas, que "junto a otras militantes femeninas, creó en 1884 la sección de trabajadoras anarco-colectivistas, siendo elegida secretaria junto a Gertrudis Fau, mientras que la presidenta fue Federación López Montenegro" (Vega, 2019). Este es el feminismo primitivo que se podría estar omitiendo en explicaciones universitarias sobre las luchas de las mujeres dentro del Estado español, exposiciones, vídeos universitarios, charlas... Hubo un alto número de mujeres que no eran procedentes de la nobleza, como lo fueron Emilia Pardo Bazán (Burdiel, 2019) o Concepción Arenal (Caballé, 2018), y pareciera que, aún, partir desde el privilegio implicara que los nombres de las privilegiadas de nacimiento prevalecieran sobre quienes lucharon desde abajo. Las luchas obreras no se muestran en ocasiones, quedan las de mujeres de orígenes privilegiados que a continuación vamos a leer (Medina, 2006; Sierra, 2002), y ello es lo que se enseñaría en algunas universidades: "En España el Feminismo se gestó de otra forma. A principios del siglo XX surgen grandes mujeres feministas: María Lejárraga (mejor conocida como María Martínez Sierra), Margarita Nelken, Clara Campoamor" (Seara, 2018: s. p.).

En todo caso, no podemos dejar de conjugar factores. Por un lado, la idea generalizada de las mujeres como ángeles del hogar, es decir, la ideología de la domesticidad en la España del siglo XIX, que era una peculiar amalgama de nociones tradicionales, ideas religiosas y valores burgueses (Aresti, 2000). Sin embargo, había 
también otro tipo de mujeres, no precisamente del tipo nobleza-liberal-burguesa, sino trabajadoras y luchadoras en la calle, no desde la pluma y el privilegio de salón: en esos años fueron realmente las mujeres obreras las que mayoritariamente se manifestaron contra las quintas y embarques y entendamos que, por ejemplo, en las protestas de Barcelona previas a la Semana Trágica, mujeres y niños eran quienes encabezaban las manifestaciones (Bermúdez, 2018).

Aún hoy, pareciera que la historia la escriben en ocasiones, o bien quienes desean solo nombrar a las representantes de su ideología, o bien quienes representan a los/as vencedores/as, que no desean mostrar los trapos sucios: en las manos del profesorado está que la enseñanza, también del feminismo, no forme parte de una didáctica de la historia, dentro del sistema instructivo vigente, que sea un proceso de domesticación de la humanidad al servicio de los/as poderosos/as (Fernández, 1998). Las feministas como Claramunt, precisamente, eran, y son, de las que no obtienen simpatías, puesto que mostraba extrema intransigencia y purismo contra todo tipo de colaboración con sectores políticos (Vicente, 2006), y ello implica que ningún grupo o individualidad académica con intereses partidistas pudiera apropiarse de su legado.

Cuestión fundamental, en líneas generales, es entender la respuesta a la situación por parte de decenas de mujeres anónimas, que ahora pueden representarse en Claramunt, dentro de un entorno en el que las mujeres se pretendía que fueran poco más que esclavas, hecho corroborado legalmente: La discriminación legal de las mujeres se garantizó, en la España de la Restauración borbónica a la que tanto contribuyó Cánovas del Castillo, a través del Código Civil (1889), Penal (1870) y de Comercio (1885) (Vicente, 2005). Es posible considerar necesario reiterar la dificultad en concebir un mundo así para las mujeres, que, burkas aparte, podrían tener hasta similitudes con el nuevo, a la par que viejo, régimen talibán reinstaurado en Afganistán, de nuevo en 2021, y hasta no se sabe qué fecha.

El objeto de este epígrafe no es realizar una revisión histórica del papel de las mujeres y de los orígenes del feminismo obrerista, si bien hemos de ser conscientes de que los estudios sobre el movimiento obrero en el Estado español se han ocupado muy puntualmente de considerar las connotaciones de género inscritas en el devenir de su pensamiento y de sus prácticas (Espigado, 2002; Puente, 2016). Es por ello, y por un mínimo de memoria histórica, que hemos de considerar la mención a dos luchadoras más del contexto catalán en el que seguimos puesto que, junto a las ya citadas, representan una base fundamental y una herencia cultural feminista para las primeras décadas antes de la involución provocada por la dictadura franquista (Lora, 2017).

Sin la investigación realizada para este artículo (a través de una metodología cualitativa de análisis documental de fuentes primarias, complementada con fuentes secundarias), nunca podría haber llegado a la conocida como primera sindicalista catalana, Isabel Vilà i Pujol. Vilá, por ejemplo, participó en el mitin de afirmación internacionalista del 30 de agosto de 1872 en Sant Feliu de Guíxols (Girona), arengando con estilo pedagógico y simple, contribuyendo a la consolidación local de la Asociación Internacional de los Trabajadores, una agrupación no precisamente republicana, sino de orientación libertaria y contra la clase política (Gelabertó, 2001). 
Teresa Mañé, que usaba el seudónimo de Soledad Gustavo, es la segunda luchadora fundamental que no puede ignorarse, bajo mi punto de vista. Amiga personal de Francisco Ferrer Guardia, estudió magisterio, sin titularse. Pese a ello, abrió una escuela para niñas en Vilanova i la Geltrú, Barcelona, y en 1888 firmó para crear la Confederación de Amigos de la Enseñanza Laica, denunciando que la mujeres recibían escasa formación por culpa, entre otras cuestiones, de la religión, presentando Mañé una consigna muy clara e inequívoca: "la mujer será lo que debe ser: libre como el hombre" (Moreno, 2004: 72).

\section{La necesidad de una investigación crítica sin omisiones}

La mencionada Teresa Mañé lo tenía claro, y así lo difundía: "critica los fundamentos de la religión; plantea que Dios no ha hecho nada para mejorar las condiciones sociales de mujeres" (Cuadrada y Puente, 2016: 32). La Escuela Moderna aún lo haría con mayor contundencia, escribiendo que, respecto a la higiene, que la suciedad católica dominaba en España (Ferrer, 2010). Probablemente sea más que necesario tener en cuenta estas cuestiones para el análisis que a continuación acontece.

Cualquier tipo de investigación en ciencias sociales que pretenda ser crítica debiera basarse, en la medida de lo posible, en las fuentes primarias. Resultado de lo contrario, sería lo que ya otrora se pudo comprobar con respecto a la Escuela Moderna: o se omite directamente de la historia de la educación, o se habla negativamente de ella sin ningún tipo de fundamentación en base primaria alguna (Nadal, 2018). Es ahora cuando se re- cuerda una cita anterior, ahora, aún, con una mayor base:

¿será cierta, también para el caso Ferrer, la desesperada afirmación de que la historia la escriben siempre los vencedores (y sus intelectuales)? Cuando ya no queda, a escala ciudadana, capacidad de reflexión ... la propaganda ... es verdad histórica (Solá, 2004: 75).

Hasta en sectores progresistas de los años justamente previos al nacimiento de la Escuela Moderna, incluso en votaciones de congresos internacionales, hasta "un $60 \%$ se mostraban contrarios a la coeducación" (Ballarín, 1989: 260). Siguiendo los posicionamientos de Claramunt, quienes por algunos sectores podrían considerarse como posibles profesionales afines, como vemos, no lo serían tanto, y por ello sería que realmente, no habría coeducación de sexos en la España de la época. Lo que impondría la Escuela Moderna iba a ser una revolución: "Incluso en las escuelas laicas -la Institución Libre de Enseñanza de Sabadell, por ejemplo- los niños estaban separados de las niñas en pisos distintos. Existía un grave prejuicio de tipo moral y social contra la educación mixta" (Delgado, 1979: 104-105). Es muy importante separar conceptos realmente opuestos, bajo mi punto de vista, y tanto el feminismo obrerista emancipador no se considera que guarde gran relación con el feminismo burgués, como la Escuela Moderna con la Institución Libre de enseñanza, donde se reproduce

el "ethos" cultural de la pequeña burguesía, se educan líderes, élite que gobierne. La Escuela Moderna, bien al contrario, lo que desea es acabar de una vez por todas con ese sistema social dentro de su campo de acción (Monés, Solá y Lázaro, 1980: 144).

Ayer y, por qué no, también hoy, es posible considerar que "en una sociedad je- 
rárquica y clasista, como ha sido siempre la española, cuestiones como el sexo, el estado civil y la clase social determinan el lugar que debe ocupar el individuo dentro de la sociedad" (Cantizano, 2004: 81). La Escuela Moderna pretendía revertir dicho proceso, igualando de forma absoluta a niñas y a niños.

Un dato, de los que hasta la fecha es difícil leer en las fuentes históricas que desprecian a la Escuela Moderna, e incluso en aquellas obras que parecieran hagiografías, es que sí hubo una mínima segregación por sexos, lo cual contrasta con, también, fuentes primarias que veremos más adelante. En el Boletín de la Escuela Moderna (1901-1903), esta recomendaba encarecidamente a cuantas sociedades e individuos se propusieran establecer escuelas racionales, las fundaran mixtas, o de ambos sexos, en las cuales niñas y niños asistieran en unión a las mismas clases para recibir la misma instrucción. Bastaría, según esta publicación, con que una hora al día, todo lo más (en la Escuela Moderna se destinaban tres horas semanales), se juntaran a las niñas para que se dedicaran a costura y bordados, mientras los niños estudiaban otra materia, que a su vez las niñas podrán estudiar fuera de clase o durante las horas de recreo.

Esta cuestión ahora mencionada sería bastante poco conocida, pudiéndose leer en el citado boletín cuatro asignaturas solo para niñas: corte y costura, flores artificiales, bordado artístico y economía doméstica. Ello sería una contradicción con todos los textos que se mencionarán a continuación, y con sus autoras, si bien no se encontraría descripción de estos hechos diferenciales y segregadores en las obras de Ferrer (2009; 2010).

Habría distintas hipótesis relacionadas con la segregación mencionada. La pri- mera de ella, el contexto patriarcal de la época, y por supuesto, que dicha segregación sexual, precisamente, sería lo que más normalizaría a la Escuela Moderna dentro de su entorno. Este centro de enseñanza comenzaría su andadura con solo doce niñas, y esta baja cifra no era en modo alguno casual, y así se expresa en su fuente primaria: consideraban que debían estar en absoluta vigilancia, en previsión de cualquier desprestigio malintencionado que, acerca de la coeducación de niñas y niños, hubieran podido introducir arteramente los rutinarios enemigos de la que sin duda era una nueva forma de entender la educación (Ferrer, 2010). Efectivamente, toda segregación, en cualquier centro, sería la norma. La unión de niñas y niños, básicamente, ya era una gran provocación. Es muy fácil la crítica descontextualizada que podemos efectuar hoy. Si analizamos todo lo descrito hasta el momento, más bien hablaremos de una valentía notoria. A veces, la investigación histórica, política y/o social, tiene unos sesgos difícilmente asumibles. El siguiente titular será una prueba de ello.

\section{Ferrer y sus mujeres... 0 el origen feminista de la Escuela Moderna}

En el primer cuarto del siglo XXI, y pese a determinada música producida, vendida y difundida por multinacionales (Guzmán, 2018; Illescas, 2019), a priori debiera pensarse que las mujeres no son propiedad de nadie, al menos, si obviamos cuestiones de proxenetismo y trata de blancas, por ejemplo. Igualmente, en ámbitos académicos, nunca consideré que existiría la posibilidad de encontrar en un libro sobre Francisco Ferrer Guardia, tomado de una 
universidad estatal, un titular del tipo Ferrer y sus mujeres, circunscrito a la vida sentimental del fundador de la Escuela Moderna. Pero así fue (Avilés, 2006). E nombre de este epígrafe es la antítesis de la filosofía y del enfoque del artículo, pero sirva de muestra para entender el nivel de lo que podemos encontrar cuando empleamos fuentes secundarias en la investigación del asunto que nos ocupa.

$\mathrm{Ni}$ en las fuentes, digámoslo así, enemigas, leí que la Escuela Moderna no pudo existir sin mujeres, que fueron la base de la institución, o que inundaron las páginas de su boletín. Pero así fue. De hecho, obviando la explicación preliminar, prácticamente el primer capítulo de La Escuela Moderna (Ferrer, 2010) es La señorita Meunié. Al igual que hoy, desde la enseñanza, a todo tipo de temáticas políticas o sociales, se abordan obviando la cuestión económica, como si el dinero, o el ánimo de lucro, no estuvieran detrás de casi todo, lo mismo sucede cuando se aborda la Escuela Moderna, focalizando todo en Francisco Ferrer Guardia, y hasta en su privada vida sentimental. Pero, bajo mi punto de vista, siempre hay que ir más allá.

A través de la masonería, en París, y una vez dominado el idioma francés, Ferrer tuvo acceso a personas de alto poder adquisitivo, dado que les impartía idioma castellano. Un par de las alumnas a las que dio clase son fundamentales en la Escuela Moderna, pero la base de la existencia de esta última es la citada Ernestina Meunié. Acaudalada, conservadora y católica convencida, evolucionó, transitó, o como se le desee considerar, a unas ideas enormemente próximas a las de Ferrer, especialmente tras un viaje con él y otra alumna más, por Europa.

El progreso hacia las ideas igualitarias, que posteriormente serían impartidas en la Escuela Moderna, en el caso de Meunié, implicó que cesara su admiración hacia el clero, el hombre y su justicia que realmente está al servicio de los poderosos, hacia el ejército que lo mismo defiende, y hacia todo lo conectado con la autoridad y el gobierno, como afirmó en una carta fechada el 2 de noviembre de 1899 (Archer, 1911), año en que participaría, con anterioridad, en el mes de junio, como representante de la Sociedad Progresiva Femenina, en la Conferencia Feminista Internacional celebrada en Londres (Arkinstall, 2014). Quizás por primera vez, en cualquier tipo de escrito sobre la Escuela Moderna, puede afirmarse, en base a la fuente anterior, que el origen de esta experiencia única, al margen de toda la tradición pedagógica libertaria previa y el contexto de la Barcelona de 1901, fue una feminista.

Si Meunié murió en la primavera de 1901, dejando una casa valorada en cerca de un millón de francos, y aún mayor herencia a Ferrer, y la Escuela Moderna inició su andadura pocos meses después, está claro con que fondos fue. Pero hemos de sumar a la historia a la segunda alumna viajera de Ferrer: Leopoldina Bonnard. No solo alumna, sino joven maestra (había sido profesora en París), sería docente de la Escuela Moderna hasta 1905 (Delgado, 1979: 115), aportó capital al proyecto, se convirtió en la segunda mujer de Ferrer (Cappelletti, 2012) y escribió, a modo de libro de texto para el centro educativo, Nociones de idioma francés, editado por la escuela.

\section{Coeducación y didáctica de las ideas iqualitarias}

Al igual que crear un oasis de libertad en prisiones se antoja una empresa de enorme complejidad, hasta ilógica, e incluso 
incoherente para el hecho punitivo que implican esas instituciones, inaugurar la coeducación de sexos en centros educativos -aún en uno solo y conocido-, la enseñanza mixta, para cualquiera que haya logrado entender la situación de las mujeres en la España de inicios del siglo XX, que logre contextualizar cuál era el status quo, ya no solo sería complejo, ilógico para la lógica de la época, o incoherente para no sufrir la represión de gobiernos políticos o de facto, sino que, bajo mi punto de vista, era casi un suicidio, colocarse prácticamente un cartel de pena de muerte en el cuerpo, como así finalmente sería.

Es el propio Ferrer (2010) el que afirmaba, literalmente, cómo se guardó bien de propagar públicamente su propósito, reservándose hacerlo privada e individualmente: a toda persona que solicitaba la inscripción de un alumno, le preguntaba si tenía niñas en su familia, siendo necesario exponer a cada padre las razones que apoyan la coeducación, y aunque el trabajo lo consideraba pesado, lo valoró como fructífero.

En el inicio de la Escuela Moderna, curso 1901-1902, se comenzaba la andadura con doce niñas y, a través del Boletín de la Escuela Moderna, a final de curso, ya se había pasado a 32 de ellas, finalizando el siguiente curso 1902-1903 con 34 niñas. Algunos de los nombres conocidos de profesoras de la Escuela Moderna fueron las hermanas María, Ángeles y Soledad Villafranca, y por supuesto, Clemence Jacquinet, primera directora del centro educativo, profusa escritora en el Boletín de la Escuela Moderna, y autora de uno de los primeros manuales de la institución, cuyo título fue Compendio de Historia Universal, editado en 1902.

La fuente primaria fundamental con la cual podemos conocer la difusión de las ideas igualitarias en la Escuela Moderna es su citado órgano de expresión, su boletín. Desde la portada de su segundo número, cuyo título fue "Necesidad de la enseñanza mixta", es decir, desde el treinta de noviembre de 1901, este espacio revolucionario se fue quitando la careta y apostando por esa igualdad que era la base de su fundación. Desde entonces, la enumeración que podría hacerse de los artículos en el boletín, apostando por la coeducación, la educación de las mujeres en sí, y las ideas igualitarias, es considerable: Letourneau: "Solidaridad de los sexos", (año I, núm. 2, 30 de noviembre de 1901), Maximiliana Biais: "Enseñanza Superior de la Mujer en Turquía", (año I, núm. 7, 31 de mayo de 1902), Ida R. Sée: "Cambios Necesarios" (año I, núm. 8, 30 de junio de 1902), Renée Rambaud: "Un Quinteto Interesante" (año II, núm. 1, 31 de octubre de 1902), René Chaughi: "La mujer esclava" (año II, núm. 3, 31 de diciembre de 1902), Odette Laguerre: "Las Estudiantas en la Universidad de París" (año II, núm. 7, 30 de abril de 1903), Juana Rino: "La servidumbre de la Mujer" (año II, núm. 7, 30 de abril de 1903), Paul Robin, "Coeducación" (año IV, núm. 4, 31 de diciembre de 1904), José Casasola, "La Educación Racional II", (año V, núm. 3, 30 de noviembre de 1905), Eva: "La Educación de la Mujer" (año II, segunda época, núm. 1, $1^{\circ}$ de enero de 1909)... (Velázquez, 2008).

Si el Boletín de la Escuela Moderna tuvo un total de 62 números -hasta que el Estado español encarceló y asesinó a Ferrer-, encontramos 31 escritos inequívocamente escritos por mujeres, en las 17 primeras publicaciones, dentro de las cuales hay un alto número de escritos sin firma, o con firma ambigua, que probablemente tuvieron como autoras a 
mujeres, especialmente a la mencionada Jacquinet (Nadal, 2019b).

Debe quedar clara la idea: no solo se unió a niños y niñas en un mismo espacio para ofrecerles las mismas oportunidades, se fue mucho más allá. Cuando hablamos de esas mismas oportunidades no hablamos de un proceso que implicara la demagógica propuesta del mismo currículo para todo el alumnado, toda la vida, sin ir más allá, sino que, establecida una mínima base, cada estudiante podía elegir estudiar e investigar aquello que quisiera, proceso que se iniciaba con el denominado primer año normal, abandonando todo aquello que no le hubiera sido útil, en ningún caso, hasta el momento. Las ideas que se expresaban en el Boletín de la Escuela Moderna por la liberación de las mujeres eran altamente explícitas en ocasiones, así como también lo era la lucha de algunas de sus autoras.

En el quinto boletín de la escuela, en un escrito (firmado por una mujer) titulado "La rémora", se podía leer sin género de dudas, y nunca mejor dicho, como una mujer se avergonzaba porque su director/confesor le prohibía realizar determinadas lecturas que contribuyeran a su liberación: el objetivo de esta joven era la salvación cristiana, y la gloria celestial. La mujer que narraba lo anterior, emancipada, calificaba a aquella sometida a la autoridad de su confesor como bella ignorante, y la conclusión del artículo es que la cadena, la venda, seguía ahí, y el confesionario seguía siendo una dura traba para el progreso.

Las ideas de igualdad trascendían e iban en la dirección de la superación de la enseñanza basada en la admiración de príncipes y princesas -como en la actualidad tenemos en los colegios el concurso, cada año, llamado Qué es un rey para ti-, y podía leerse como no todo el mundo vestía como la nobleza de las capitales, la rusticidad era simpática y franca, y una muchacha limpia y laboriosa podía gozar de la paz del alma y de la salud del cuerpo: había que huir de la impertinencia y vanidad, también, de las bachilleres y de sus vestidos de seda, todo ello a través de un texto, no firmado, en el sexto boletín de la escuela, con el título "Pensando en vosotros".

En este mismo último boletín mencionado también encontramos un texto, metafórico, por el progreso, titulado "El manantial y la balsa", pero lo más importante es quien Io firma: Odette Laguerre (1903a), fundadora en Francia de "Educación y Acción Feminista" (McMillan, 2000: 213). Junto con la también feminista francesa Ida R. Sée, también firmarían el escrito, anteriormente mencionado y citado, titulado "Cambios necesarios", y él se expresaba claramente como era necesario que las jóvenes cesaran para siempre de ser esos preciosos cachivaches de lujo que eran hasta la edad de veinte o veinticinco años, pasando después a convertirse en seres desgraciadamente impersonales y amorfos cuando el matrimonio no les completaba: debían disponerse a vivir una vida propia, con lo que seguramente podrían desarrollar nuevas y poderosas energías, y actuar de forma positivamente racional y humana. Como podemos observar, la educación y la difusión que pretendía efectuar el órgano de expresión de la Escuela Moderna iba más allá de las niñas del centro, alcanzando a sus madres y a la población en general.

La importancia de Laguerre (1903b) es fundamental, así como la claridad de sus escritos, siendo la Escuela Moderna una de sus introductoras en Barcelona, y con ello, en el territorio ibérico. En 1905, sin 
ir más lejos, la francesa Sociedad de Educación y Acción Feministas le publicaría, dentro de su colección Educación Feminista, su libro titulado Qué es el feminismo. Es tal la trascendencia de este escrito que tanto la Biblioteca Nacional de Francia como la multinacional Hachette Livre lo volvieron a editar en octubre del año 2014.

Atendiendo al respeto fundamental a la fuente primaria, probablemente, no hay mejor forma de darnos cuenta de hasta qué punto llegaba la claridad y la expresión de ideas de esta valiosa mujer que la transcripción directa de lo por ella firmado en el número 8, año II, del Boletín de la Escuela Moderna publicado el 31 de mayo de 1903 bajo el título "Trabajos manuales":

Explicadme por qué las manos de la mujer, mejor que las del hombre, hayan sido hechas para barrer, lavar, coser, encender el fuego o remover una salsa.

El hombre, dirán, se ha reservado los trabajos que exigen fuerza muscular, y ha dejado a la mujer los que exigen especialmente destreza y paciencia.

No veo que vigor de bíceps reclama el oficio de farmacéutico, ... ni en el de relojero, ... ni en el de expedicionero, ni muchas otras profesiones sedentarias acaparadas por los hombres.

En Turquía los soldados hacen media, y nadie lo encuentra raro; pero suponed en Francia o en España un hombre haciendo media ...

No deben deducirse de estas observaciones que ha de trastornarse todo en nuestro sistema de educación manual, enseñando a los niños la cocina y la costura, y a las niñas la carpintería y la horticultura. No trastornaremos nada. Preferimos la evolución a la revolución.

Lo que podemos razonablemente pedir es que por la educación manual, como por la educación intelectual, se eleve el nivel del saber femenino y se atenúe la preocupación de la desigualdad de los hechos. Ya es tiempo de enseñar a los niños que no hay trabajo despreciable para ellos que sea bueno para las niñas (10).

Quizás lo dejaron pasar por alto, pero párrafos anteriores, podía leerse "Las Estudiantas en la Universidad de París", y no, no es una errata, es un lenguaje inclusivo primitivo y sin miedos. Además, las ideas de dicho texto, de nuevo, son inequívocas, y nada mejor que citarlas, de nuevo, textualmente, como muestra de respeto, e incluso, de admiración:

1. Una joven que se respeta sabe hacerse respetar en todas partes y no tiene necesidad de que su virtud sea rodeada de vigilantes. La mejor protección que puede dársele consiste en desarrollar en ella el sentimiento de su dignidad, y, por tanto, en favorecer la extensión y la consistencia de su personalidad en vez de restringirla, como se ha hecho hasta aquí.

2. La presencia de las mujeres en las reuniones públicas, lejos de ser un elemento de desorden, es, por el contrario, una condición favorable que se impone a todos los principios de conveniencia, de cortesía y de moralidad que los hombres olvidan harto fácilmente entre sí.

3. La coeducación, que aproxima los sexos en un pensamiento serio, en un objeto útil, en una labor común, no ofrece ninguno de los peligros que nacen precisamente de la separación de los sexos, de la ignorancia en que se hallan el uno del otro, de no conocerse, de no mirarse recíprocamente más que con preocupaciones sentimentales o sensuales. 
El interés intelectual que despierta el estudio hecho en común aparta los ensueños románticos, así como los fomentan nuestras rancias costumbres actuales (1903:6).

Bajo mi punto de vista, aún hoy, en demasiadas ocasiones, es difícil encontrar reflexiones, por ejemplo, de la contundencia de las últimas dos líneas. Y ello en el caso de que realmente hayamos superado todas las rancias costumbres de hace más de un siglo.

\section{Conclusiones}

Probablemente, de las mejores maneras que hay de transmitir las ideas igualitarias es poniéndolas en práctica. Y cuando desde la teoría se está en el camino, pudiera ser que este pudiera emprenderse:

la mujer no debe estar recluida en el hogar. El radio de su acción ha de dilatarse fuera de las paredes de las casas: debería ese radio concluir donde llega y termina la sociedad. Más para que la mujer ejerza su acción benéfica, no se han de convertir en poco menos que en cero los conocimientos que le son permitidos: debieran ser en cantidad y en calidad los mismos que el hombre se proporciona (Ferrer, 2010: 105).

Las mujeres, así se entendía en este espacio pedagógico, lo podían todo. No debía tener ningún límite en su formación, en su desarrollo, en su expansión, hasta lograr una igualdad, la cual no era dentro del capitalismo, sino dentro del mundo nuevo, libertario, al que aspiraban tanto Ferrer como la Escuela Moderna. Tener medios, difundir ideas abiertamente feministas, construir una alternativa real, ofrecer misas de la ciencia los domingos, y hasta tratar de impartir educación sexual... en aquella época, y aún hoy en determina- dos territorios, son una pena de muerte. $\mathrm{Y}$ así fue.

El resultado de evaluar la didáctica de las ideas igualitarias de la Escuela Moderna, a través de la fuente primaria que es su boletín, es algo al alcance de cualquier investigadora o investigador, y ofrece, siempre, una amalgama de resultados, en muchos de los cuales es más que sorprendente ver en la fecha que estaban datados los escritos, y dentro de qué contexto. La igualdad habría sido la máxima, y ella se producía a través de todos los medios de los que la escuela disponía, que eran básicamente los que Ferrer había recibido a través de una mujer, como vimos. Por supuesto, la máxima, tras siglos de opresión, que obviamente, hacen mella.

Al igual que se mira para otro lado al aflorar el tema de la esclavitud y la muerte tras el coltán, o de la explotación laboral extrema que hay tras nuestra tecnología, ropa o fuentes de energía, o de cómo las mujeres siguen sin derechos humanos en tan alto número de lugares -siendo un lugar, bajo mi punto de vista, ya un alto número, en este caso-, hemos de considerar, a la hora de hablar de transmisión de ideas igualitarias, que quizás hubiera, antes de lo que nos contaron, y de quienes nos contaron, mujeres, y hombres, que ya lucharon por ello, y que en lugar de premios, pagaron con exilio, e incluso muerte, su verdadero anhelo de igualdad. Va por todas ellas, y ellos, este texto. Por los/as olvidados/as, los/as anónimos y, por supuesto, los/as silenciados/as.

\section{Bibliografía}

Archer, W. (1911). The life, trial, and death of Francisco Ferrer. New York: Moffat, Yard and Company. 
Aresti, N. (2000). "El ángel del hogar y sus demonios: Ciencia, religión y género en la España del siglo XIX." Historia contemporánea, 21, 363-394. DOI: https:// doi.org/10.1387/hc. 15898

Arkinstall, C. (2014). Spanish Female Writers and the Freethinking Press, 18791926. Toronto: University of Toronto Press.

Avilés, J. (2006). Francisco Ferrer y Guardia. Pedagogo, anarquista y mártir. Madrid: Marcial Pons, Ediciones de Historia.

Ballarín, P. (1989). "La educación de la mujer española en el siglo XIX." Historia de la educación: Revista interuniversitaria, 8, 245-260. DOI: 10.14201

Bermúdez, A. (2018). "El discurso católico ante la Semana Trágica y el Barranco del Lobo de 1909." Revista Digital Guerra Colonial, 3, 5-22. http://www.guerracolonial.es/medias/files/3.1.-el-discurso-catolico-ante-la-semana-tragica-y-el-barranco-del-lobo-5.pdf

Boletín de la Escuela Moderna (19011903). Año I (Núm.1-8), Año II (Núm. 1-9). http://biblioteca.ferrerguardia.org/ fons/arxiu-digital-ffg/publicacions-i-documents/boletin-de-la-escuela-moderna. 11/09/2021.

Burdiel, I. (2019). Emilia Pardo Bazán. Españoles eminentes. Barcelona: Editorial Taurus.

Caballé, A. (2018). Concepción Arenal, la caminante y su sombra. Barcelona: Editorial Taurus / Fundación Juan March.

Cantizano, B. (2004). "La mujer en la prensa femenina del XIX." Ambitos: Revista internacional de comunicación, 11-12, 281-298. http://hdl.handle. net/11441/67571
Cappelletti, A. (2012). Francisco Ferrer y la pedagogía libertaria. Madrid: Tierra de Fuego / LaMalatesta Editorial.

Cuadrada, C. y Puente, G. (2016). "A debate: entre "feminismo» anarquista y el feminismo burgués." Feminismo/s, 28, 25-47. DOI: http://dx.doi.org/10.14198/ fem.2016.28.01

Di Paola, P. (2021). "Una furiosa paladina della bontà: Louise Michel, emozioni, carisma e anarchia." Memoria e ricerca, 67(2), 295-312. DOI: 10.14647/100881

Delgado, B. (1979). La Escuela Moderna de Ferrer i Guardia. Barcelona: Ceac.

Espigado, G. (2002). "Las mujeres en el anarquismo español (1869-1939)." Ayer, Revista de Historia, 45, 39-72. http:// www.jstor.org/stable/41324839

Fernández, A. R. (2018). Reformulaciones en la enseñanza de la historia. Feminismo para alumnos universitarios de Didáctica de las Ciencias Sociales. Departamento de Didáctica de las Ciencias Sociales. Facultad de Ciencias de la Educación. Universidad de Granada.

Fernández, M. (1998). La cara oculta de la escuela: educación y trabajo en el capitalismo. Madrid: Siglo XXI Editores.

Ferrer, F. (2009). Principios de moral científica. Barcelona: Fundació Ferrer i Guárdia.

Ferrer, F. (2010). La Escuela Moderna. Edición de Luis Miguel Lázaro, Jordi Monés y Pere Solá. Madrid: Editorial Biblioteca Nueva.

Gelabertó, J. C. (2001). "Isabel Vilá, de Llagostera, Iluitadora social i pedagoga." Revista de Girona, 205, 32-35. https:// revistes.udg.edu/revista-girona/article/ download/15339/19185 
Guzmán, J. (1 de noviembre de 2018). La polémica que encierra la letra de Romeo Santos en "Quiere Beber (Remix)". Heabbi. https://heabbi.com/polemicaletra-romeo-quiere-beber. 30/08/2021.

Illescas, J. E. (2019). Educación Tóxica: El imperio de las pantallas y la música dominante en niños y adolescentes. BarceIona: El Viejo Topo.

Laguerre, O. (1903a). "Trabajos manuales." Boletín de la Escuela Moderna, Año II (núm. 8), 9-10. http://biblioteca.ferrerguardia.org/fons/arxiu-digital-ffg/publicacions-i-documents/boletin-de-la-escuelamoderna

Laguerre, O. (1903b). "Las estudiantas de la Universidad de París." Boletín de la Escuela Moderna, Año II (núm. 7), 6. http://biblioteca.ferrerguardia.org/fons/arxiu-digital-ffg/publicacions-i-documents/ boletin-de-la-escuela-moderna

Ley 14/1975, de 2 de mayo, sobre reforma de determinados artículos del Código Civil y del Código de Comercio sobre la situación jurídica de la mujer casada y los derechos y deberes de los cónyuges. BOE, 107, 9413-9419.

Lora, A. (2017). "La visión ontológica de la mujer y el hombre en el anarquismo español de los años treinta: identidad y género a debate." Brocar: Cuadernos de investigación histórica, 41, 153-175. DOI: http://doi.org/10.18172/brocar.3412

Marín, D. (2009). La Semana Trágica: Barcelona en llamas, la revuelta populary la Escuela Moderna. Madrid: La Esfera de los Libros, S. L.

Martín de Santa Olalla, P. (2001). "La ley del divorcio de junio de 1981 en perspectiva histórica." Espacio, Tiempo y Forma, Serie V, Historia Contemporánea,
14, 519-551. http://e-spacio.uned.es/fez/ eserv/bibliuned:ETFSerie5-ECOFOCAC8682-0A4B-2456-69B706986498/Documento.pdf

McMillan, J. F. (2000). France and Women, 1789-1914: Gender, Society and Politics. London: Routledge.

Medina, R. (2006). "Kilpatrick, Susan. Mujer, modernismo y vanguardia en España (1898-1931). Madrid: CátedraFeminismos, 2003. 322 pp." Letras Femeninas, 32(2), 227-229. https://revistas.unav.edu/index.php/rilce/article/ view/26631

Monés, J., Solá, P. y Lázaro, L. M. (1980). Ferrer Guardia y la pedagogía libertaria: elementos para un debate. Barcelona: Icaria Editorial.

Montagut, E. (16 de agosto de 2010). "Breve historia del feminismo en Cataluña hasta el final de la guerra civil." El País. http://lacomunidad.elpais.com/memoriahistorica/2010/8/16/breve-historia-delfeminismo-cataluna-2. 30/06/2021.

Moreno, M. (2004). "Racionalismo y socialización femenina: vivir en laico." Arenal: Revista de historia de las mujeres, 11(2), 57-85. http://hdl.handle. net/10045/56925

Nadal, A. (2018). La Escuela Moderna. Análisis histórico. Madrid: La Muralla.

Nadal, A. (2019a). Análisis y valoración de la metodología activa e innovadora de la Escuela Moderna de Francisco Ferrer Guardia en su primer curso académico. De las lecciones de cosas al trabajo individual. En Baena, A. y Ruiz, P. J. (Eds.) (2019). Metodologías activas en Ciencias de la Educación. Vol. I. Sevilla: Wanceulen Editorial.

Nadal, A. (2019b). La mujer como autora en el Boletín de la Escuela Moderna en su 
primera época (1901-1903). En SuárezVillegas, J.-C., Marín-Conejo, S. y Panarese, P. (Coords.), Comunicación, género y educación: representaciones y (de)construcciones (167-170). Madrid: Editorial Dykinson.

Nerín, N. (1 de mayo de 2018). "Ciudadanos se hace un lío con Clara Campoamor, muerta en el exilio en Suiza." El Nacional. https://www.elnacional.cat/es/ cultura/ciudadanos-clara-campoamor-albert-rivera-feminismo_263772_102.html. 11/09/2021.

Ortega, M. (1 de agosto de 2016). "Feministas de camisa negra: de la lucha por el sufragio al fascismo." El Confidencial. https://www.elconfidencial. com/cultura/2016-08-01/feministascamisa-negra-sufragio-fascismo-granbretana_1240743/. 10/09/2021.

Puente, G. (2016). De Soledad Gustavo a Teresa Mañé (1865-1939) (Tesis de Máster en Estudios de Mujeres, Género y Ciudadanía). Instituto Interuniversitario de Estudios de Mujeres y Género (IIEDG), Universidad de Barcelona, Universidad Autónoma de Barcelona, Universidad de Gerona, Universidad Politécnica de Cataluña, Universidad Rovira i Virgili, Universidad de Vic, Universidad de Lérida, Universidad Pompeu Fabra.

Pradas, M. A. (2006). Teresa Claramunt, la virgen roja barcelonesa. Biografía y escritos. Barcelona: Virus Editorial.

Rodríguez, J. R. (2019). Cien años de desigualdad. La situación legal de la mujer española durante el siglo XX. XI Congreso virtual sobre Historia de las Mujeres (15 al 31 de octubre de 2019). Comunicaciones, 693-724. https://dialnet.unirioja.es/servlet/articulo?codigo $=7315026$
Rubí, G. (2011). "Protesta, desobediencia y violencia subversiva. La Semana Trágica de julio de 1909 en Cataluña." Pasado y Memoria. Revista de Historia Contemporánea, 10, 243-268. https://rua. ua.es/dspace/bitstream/10045/24265/1/ PYM_10_11.pdf

Saloma, A. (2000). "De la mujer ideal a la mujer real. Las contradicciones del estereotipo femenino en el siglo XIX." Cuicuilco, 7(18), 1-18. https://revistas.inah.gob. mx/index. php/cuicuilco/article/view/368

Seara, M. (2018). "Historia del Feminismo en España." Voces Visibles. https:// www.vocesvisibles.com/historia-del-feminismo-en-espana/. 10/09/2021.

Sierra, V. (2002). "Escribir y servir: las cartas de una criada durante el franquismo." SIGNO. Revista de Historia de la Cultura Escrita, 10, 121-140. https:// ebuah.uah.es/dspace/bitstream/handle/10017/7587/escribir_sierra_SIGNO_2002. pdf?sequence $=1$ \&isAllowed $=y$

Solá, P. (2004). "El honor de los estados y los juicios paralelos en el caso Ferrer Guardia. Un cuarto de siglo de historiografía sobre la «Escuela Moderna» de Barcelona." Cuadernos de Historia Contemporánea, 24, 49-75. https://revistas. ucm.es/index.php/CHCO/article/view/ CHC00404110049A

Velázquez, P. (2008). La Escuela Moderna. Una editorial y sus libros de texto (1901-1920) (Tesis Doctoral). Departamento de Teoría e Historia de la Educación, Facultad de Ciencias de la Educación, Universidad de Murcia.

Vega, E. (21 de septiembre de 2019). "¿Una presencia marginal? Mujeres y militancia en el anarquismo español." Ser Histórico. Portal de historia. https://serhistorico.net/2019/09/21/una-presencia- 
marginal-mujeres-y-militancia-en-el-anarquismo-espanol/. 11/09/2021.

Vicente, L. (2005). "Teresa Claramunt, memoria y biografía de una heterodoxa." Arenal: Revista de historia de las mujeres, 12(2), 281-307. DOl: https://doi. org/10.30827/arenal.v12i2.2985

Vicente, L. (2006). "Los inicios del feminismo en el obrerismo catalán. Un folleto de Teresa Claramunt." Arenal: Revista de historia de las mujeres, 13(1), 183-194. DOI: $\quad$ https://doi.org/10.30827/arenal. v13i1.2996

Zarraluqui, L. (2012). "Eficacia de los pactos familiares." Revista de Derecho, Empresa y Sociedad (REDS), 1, 1-56. https://vlex.es/vid/eficacia-pactos-familiares-500697866 